\title{
LIBERDADE DE IMPRENSA E AUTORIDADES PÚBLICAS: APONTAMENTOS A PARTIR DO ESTADO DEMOCRÁTICO DE DIREITO
}

\author{
Marcelo Andrade Cattoni de Oliveira ${ }^{1}$ \\ Maria Fernanda Salcedo Repolês ${ }^{2}$ \\ Francisco De Castilho Prates ${ }^{3}$
}

\begin{abstract}
Resumo
O artigo busca trabalhar a liberdade de imprensa, seu papel e seus limites, a partir do paradigma do Estado Democrático de Direito, no qual, a exigência de transparência e publicidade é um verdadeiro imperativo constitucional na condução das ações e políticas públicas. $\mathrm{O}$ enfoque se dá na relação entre o papel investigativo da imprensa diante das chamadas autoridades públicas. Isto é, perguntamos se estas autoridades, quanto a assuntos que gravitam em torno de suas funções e responsabilidades, teriam ou não a mesma relação com a liberdade de imprensa que os demais cidadãos. Para este fim, sem olvidarmos de nosso próprio contexto constitucional, decidimos dialogar com o direito comparado, principalmente com o cenário estadunidense e certas decisões da Suprema Corte dos Estados Unidos que lidam com a mesma temática aqui abordada. Concluise que a liberdade da imprensa tem um papel essencial, constitucionalmente reconhecido, no Estado Democrático de Direito.
\end{abstract}

Palavras-Chave: Liberdade de Imprensa; Limites; Autoridades Públicas; Estado Democrático de Direito.

\section{INTRODUÇÃO}

Imaginemos uma série de reportagens em que se noticiam que este ou aquele agente público está envolvido em alguma situação de improbidade administrativa, ou que esta ou aquela denominação religiosa pode estar ludibriando seus fiéis, ou, quem sabe, coloque em discussão dados e informações que digam respeito a projetos de Estado ${ }^{4}$. Radicalizando, tomemos um jornalismo investigativo como o realizado, nos anos 70, pelo

\footnotetext{
${ }^{1}$ Pós-Doutor pela Facoltà di Lettera ed Filosofia della Università degli studi di Roma III. Professor Associado IV de Direito Constitucional e Teoria da Constituição da FD/UFMG. Subcoordenador do Programa de Pós-Graduação em Direito da UFMG. Bolsista de Produtividade do CNPq (1D).E-mail: mcattoni@gmail.com

2 Pós-Doutora pela Universidade Federal do Rio de Janeiro. Professora Adjunta IV da FD/UFMG. E-mail: mariaf.salcedo@gmail.com

${ }^{3}$ Pós-Doutorando em Direito na Faculdade de Direito da UFMG (Bolsista da Capes). E-mail: castilho_2011@yahoo.com.br

${ }^{4}$ Caso exemplificativo é o chamado Pentagon Papers, o qual envolvia a possibilidade ou não, dos jornais New York Times e Washington Post, publicarem matérias baseadas em documentos classificados como de segurança nacional. Em New York Times Co. v. United States (1971), a maioria da Supreme Court decidiu que impedir os jornais de publicarem as referidas matérias violava a liberdade de expressão e de imprensa, garantidas pela Primeira Emenda, já que não havia justificativas suficientes para uma restrição prévia (prior restraint). Ver, entre outros: (FISS, 2005: 36-37).
} 


\section{$\underline{\text { Washington Post, o célebre Watergate. }} \underline{\underline{5}}$}

Talvez, neste momento, pudéssemos recuperar o caso do jornal paranaense Gazeta do Povo ${ }^{6}$, o qual, após publicar matéria, em fevereiro de 2016, que questionava o impacto de auxílios e indenizações recebidas por membros do Poder Judiciário e do Ministério Público daquele Estado sobre o chamado teto constitucional remuneratório, foi contestado por entidades representativas daquelas duas instituições, além de terem sido ajuizadas uma série de ações judiciais por danos morais, sempre em Juizados Especiais, impetradas por magistrados e membros do Ministério Público que se consideraram ofendidos pela forma como as notícias sobre suas remunerações foram apresentadas à sociedade. ${ }^{7}$

Em razão do impacto das reportagens, o jornal publicou, ainda em fevereiro, um editorial nomeado "Debate público e respeito às instituições" ${ }^{8}$, no qual ressalta o enorme respeito e reconhecimento pelo Poder Judiciário e pelo Ministério Público, anotando que ambos são essenciais na afirmação da democracia constitucional, além de afirmar que a publicação não teve, em tempo algum, intuito de ofender estas duas instituições.

O mesmo editorial ainda escreve que os textos publicados "[...] em nenhum momento imputam às instituições ou aos seus membros a prática de ilegalidades”, também realçando o fato de que, segundo interpretação do "Conselho Nacional de Justiça (CNJ") e do "Conselho Nacional do Ministério Público (CNMP) ", os referidos componentes agregados", não extrapolam o teto remuneratório constitucionalmente previsto.

Em síntese, o editorial pauta-se pela tese de que o debate sobre temas de interesse público deve ser construtivo e amplo, mas também não deixa de lamentar o fato de que certas passagens e frases empregadas na matéria podem ter gerado "desconforto" a alguns dos membros do Poder Judiciário e do Ministério Público, mas que tal "dureza" não era o objetivo central da publicação.

A mesma Gazeta do Povo, em outro editorial, publicado em junho, denominado "As instituições e a liberdade de imprensa", ressaltou, mais uma vez, que as reportagens visavam "promover o debate crítico acerca do real sentido do teto constitucional para carreiras públicas jurídicas", afirmando, em seguida, que teria havido uma "incompreensão a respeito dessas reportagens", colocando que as mesmas, em qualquer momento, pretenderam

\footnotetext{
${ }^{5}$ Sobre o caso, conferir: <https://www.washingtonpost.com/politics/watergate/>. Acesso em: 20/06/2016.

${ }^{6}$ Disponível em: <http://www.gazetadopovo.com.br/vida-publica/tj-e-mp-pagam-supersalarios-que-superam-em-20-o-tetoprevisto-em-lei-8p4mx7sxjog1r9rivs 1hlrig7>. Acesso em: 11/06/2016.

${ }^{7}$ Por todos conferir: <http://g1.globo.com/pr/parana/noticia/2016/06/jornalistas-que-divulgaram-salarios-de-magistrados-saoalvos-de-acoes.html>; <http://wwwl.folha.uol.com.br/poder/2016/06/1778916-magistrados-entram-com-dezenas-de-acoescontra-jornalistas-no-pr.shtml>. Acessos em: 10/06/2016.

${ }^{8}$ Disponível em: <http://www.gazetadopovo.com.br/opiniao/editoriais/debate-publico-e-respeito-as-instituicoes88wdg4xlz23gdp632ntbzr7um>. Acesso em: 22/06/2016.
} 
"representar um menoscabo às instituições e aos profissionais".

De outro lado, ainda dentro da repercussão da publicação, foi exercido, em conjunto, o direito constitucional de resposta pela Associação dos Magistrados Paranaenses e pela Associação Paranaense do Ministério Público ${ }^{10}$. Nesta resposta, estas associações, entre vários pontos, colocaram que, ao contrário do que havia sido divulgado pela Gazeta do Povo, não ocorreu pagamentos superiores ao teto constitucionalmente estabelecido, mas sim, o recebimento de verbas de caráter indenizatório que, por sua específica natureza, não estão limitados ao referido teto. Em suma, para as citadas associações, os valores porventura recebidos, estavam de acordo com a legislação e a Constituição.

Estas associações também destacaram que há uma ampla publicidade, via sites eletrônicos oficiais, de todos os dados remuneratórios, o que possibilita ampla fiscalização por parte da sociedade. Além disso, ressaltam que a liberdade de imprensa é fundamento da democracia constitucional, não estando sujeita a restrições prévias, censuras, mas que tal circunstancia não torna os meios jornalísticos imunes a responsabilizações posteriores, quando agem de modo abusivo e ilegítimo, transcendendo o campo da crítica informativa, o que, segundo ainda as associações representativas, teria ocorrido com a reportagem sobre o teto remuneratório levada a efeito pelo Gazeta do Povo.

Em suma, seriam as possíveis inexatidões, os dados coletados de modo inadequado, aliado ao emprego de expressões e adjetivos tidos como ofensivos, que configurariam um quadro de desinformação, o que colocaria a Gazeta do Povo para além do campo protetivo da liberdade de imprensa, possibilitando o questionamento judicial daqueles que se sentiram atingidos em sua imagem e honra pela matéria divulgada.

Saliente-se também que reportagens e questionamentos como os produzidos pela Gazeta do Povo não são exclusivos do Paraná nem passaram a ocorrer apenas neste ano, haja vista que podem ser encontradas matérias referentes a diversas outros estados da federação, o que reforça a tese de que é, verdadeiramente, um tema constitucional, dizendo respeito a toda a sociedade. ${ }^{11}$

Em outros termos, podemos verificar que já faz algum tempo que a mídia tem se debruçado sobre indagações que gravitam sobre o teto constitucional remuneratório de magistrados e membros do Ministério Público e o recebimento de "auxílios e parcelas indenizatórias". Podem ser encontradas, inclusive, matérias que questionam, profundamente, certas propostas para uma futura Lei Orgânica da Magistratura Nacional

\footnotetext{
${ }^{9}$ Disponível em: <http://www.gazetadopovo.com.br/opiniao/editoriais/as-instituicoes-e-a-liberdade-de-imprensae7o0uel0612t82egy0qmsiuyg >. Acesso em: 12/06/2016.

10 Disponível em: <http://www.amapar.com.br/imprensa/noticias/item/direito-de-resposta-conferido-à-amapar-e-àapmp.html>. Acesso em: 22/06/2016. Ver, também: Nota de Esclarecimento. Disponível em: <http://www.amapar.com.br/imprensa/noticias/item/amapar-e-apmp-emitem-nota-de-esclarecimento-em-face-demat\%C3\%A9ria-jornal\%C3\%ADstica-que-trata-dos-vencimentos-de-magistrados-e-membros-do-mp.html>. Acesso em: 22/06/2016.

11 Conferir: <http://epoca.globo.com/tempo/noticia/2015/06/juizes-estaduais-e-promotores-eles-ganham-23-vezes-mais-dovol.10, no. 01, Rio de Janeiro, 2017.pp.219-240 
(Loman). ${ }^{12}$

No entanto, em razão dos questionamentos judiciais, a situação tomou ares maiores, levantando indagações e problematizações sobre se estaria ou não havendo uma ilegítima restrição do direito fundamental a uma imprensa livre e não intimidada, ou se o exercício do direito constitucional de ação, por parte daqueles que se sentiram ofendidos pela reportagem, estaria a demonstrar que teria ocorrido um abuso da liberdade de imprensa. ${ }^{13}$

Diante de situações como as acima elencadas, indagamos: qual o âmbito normativo da liberdade de imprensa? Poderia ela ser responsabilizada por fazer emergir temas polêmicos que envolvam, direta ou indiretamente, atividades e condutas estatais? Ou questionar figuras e autoridades públicas? Como fica a privacidade destes públicos? Ou seja, para que tal responsabilização possa ser traduzida como constitucionalmente adequada, qual ou quais critérios devem ser adotados pelos órgãos julgadores?

Em outras palavras, quando o fato ou a situação a ser narrada, por exemplo, por um jornal ou uma revista, envolve temas que, claramente, fazem parte de uma agenda pública de debates, de uma sociedade que possui o direito constitucional de ser informada, como estas fronteiras entre uma conduta jornalística abusiva e outra legitimada e protegida pelo direito fundamental à liberdade de expressão e de imprensa devem ser conformadas?

Deste modo, qual o papel esperado dos órgãos jornalísticos e de comunicação em um Estado Democrático de Direito que se considera aberto e plural? Há limites? Existindo estes, operariam no mesmo sentido tanto em relação às chamadas "pessoas comuns", quanto diante de personalidades e figuras públicas ou das autoridades do Estado?

Procurando responder a indagações como as acima formuladas, e sabedores do limite humano de qualquer ato de conhecer, ainda mais quando o espaço e tempo que aqui possuímos é por demais exíguo, propusemo-nos a uma jornada que nos levará por certas decisões e posturas argumentativas que entendemos que podem iluminar a relação, sempre tensa, entre liberdade de imprensa, democracia e os agentes de um Estado que se afirmar democrático e constitucional.

\footnotetext{
que-voce.html>. Acesso em: 10/06/2016.

${ }_{12}$ Disponível em: <http://www1.folha.uol.com.br/poder/2015/05/1632911-projetos-do-stf-criam-auxilios-do-berco-ao-caixaopara-magistrados.shtml>. Acesso em: 11/06/2016.

${ }^{13}$ Por oportuno, obervamos que, no dia 01 de julho, em juízo de retratação, a Ministra do Supremo Tribunal Federal, Rosa Weber, determinou a suspensão dos efeitos da sentença condenatória já proferida contra o jornal Gazeta do Povo, além disso, também suspendeu o procedimento de "ações judiciais padronizadas"impetradas contra o referido periódico. Esta decisão ocorreu no bojo de Agravo Regimental na Reclamação 23899, interposto pela editora responsável pelo citado jornal e pelos jornalistas e editores que participaram das reportagens. Entre outros argumentos, os impetrantes baseiam-se naquilo que foi decidido, pelo mesmo STF, quando do julgamento das ADPF 130 e ADI 4451, que julgaram não recepcionada, pela atual Constituição da República, a Lei 5.250/1967, denominada Lei de Imprensa. Neste sentido, ver: <http://www.stf.jus.br/portal/cms/verNoticiaDetalhe.asp?idConteudo=320185>. Para a íntegra da decisão da Ministra Rosa
} Weber, conferir: <http://www.stf.jus.br/arquivo/cms/noticiaNoticiaStf/anexo/RCL23899.pdf>. Acessos em: 02/07/2016. 


\section{LIBERDADE DE IMPRENSA: ENTRE LUZES E SOMBRAS}

Começamos nosso caminhar com Louis Brandeis, um dos mais lembrados juízes da Suprema Corte dos Estados Unidos que, uma vez, em 1913, publicou um artigo intitulado "What publicity can do", em que escreve que "sunlight is said to be the best of disinfectants; electric light the most efficient policeman" (BRANDEIS, 1913: 10).

Já Norberto Bobbio, por sua vez, anota que "a opacidade do poder é a negação da democracia" (BOBBIO apud SARMENTO, 2015: 07). Nesta mesma linha, o mesmo pensador italiano, em O Futuro da democracia (BOBBIO, 2006), ainda refletindo sobre a intrínseca e tensa relação entre democracia e transparência, destaca que o segredo, o que é colocado imune ou acima do debate público, não pode ser a regra do jogo democrático, mas, ao contrário, este regime deve caminhar, precípua e predominantemente, por arenas da mais extensa visibilidade, da mais ampla publicidade.

Partindo de falas como as acima expostas, visualizamos que há uma exigência constitucional e democrática de transparência no trato da coisa pública, abrindo espaço para indagações sobre a organização e as condutas funcionais dos servidores públicos, dos agentes políticos e dos membros dos poderes do Estado, haja vista que, do contrário, teremos não a defesa de direitos, como, por exemplo, o da privacidade, mas a emergência de interesses meramente egoísticos, a busca pela persistência de ilegítimos, pois injustificáveis e indefensáveis, privilégios.

Com efeito, se formos ao nosso atual contexto jurídico-constitucional, a publicidade revela ser a regra, ainda mais quando se trata de aferir não só a legalidade de condutas de autoridades e outros agentes públicos ${ }^{14}$, mas também sua legitimidade, o que pode ser verificado por uma série de mecanismos legislativos em que audiências e chamadas públicas, ou os denominados orçamentos participativos, funcionam como ferramentas normativas que pretendem aproximar o aparato estatal da sociedade, através do emprego de meios decisórios mais claros e acessíveis, ou seja, democráticos.

A opção por este paradigma que valoriza a claridade, a abertura comunicativa, que expõe as atividades públicas, lato sensu, a constantes escrutínios por parte de uma cidadania concebida discursiva e dialogicamente, que desnaturaliza conchavos, ações entre amigos e reuniões sigilosas quando o tema a toda sociedade interessa, fica ainda mais nítida, por exemplo, nos incontáveis portais da transparência hoje existentes, que disponibilizam uma série de informações a respeito da máquina pública a toda sociedade, incluindo tabelas remuneratórias dos

\footnotetext{
${ }^{14}$ Aproveitamos esta passagem para advertir que, em virtude do recorte por nós realizado, traduziremos o termo "public official" como "agentes públicos", abarcando, dentro das situações analisadas, as chamadas autoridades públicas, como, por exemplo, magistrados e membros dos ministérios públicos. Isto é, aquilo que alguns denominam de "agentes políticos" (MEIRELLES, 2001: 71-73) e outros doutrinadores, com quem nos identificamos, chamam de "servidores públicos especiais". (CARVALHO FILHO, 2014: 601)
} 
diversos quadros funcionais.

Estas posturas resultam de legislações como a chamada Lei de Acesso à informação e transparência pública (Lei 12.527/2011), em que a regra é sempre a transparência no que tange ao Estado, o que é explicitado na sua exposição de motivos, em que podemos ler que "a garantia do direito de acesso a informações públicas como regra geral é um dos grandes mecanismos da consolidação dos regimes democráticos", configurando, "o acesso a informação pública, portanto, como expressão de transparência pública [...]”15

Registre-se, desde já, que esta linha argumentativa, em hipótese alguma, está a esquecer que não existe liberdade ou transparência total, pois tal seria uma contradição em termos, mas sim que as fronteiras destas devem operar como condição de possibilidade do próprio jogo democrático. Ou seja, se tomarmos a nossa Constituição, veremos que esta, ao mesmo tempo que garante o direito de acesso a informações sobre atos do governo (art. $5^{\circ}$, par. 3ㅇ, II), também exige o respeito a intimidade e à vida privada (art. 5, X e XXXIII), além de hipóteses referentes a sigilos imprescindíveis à segurança da sociedade e do Estado, possibilitando, sempre, responsabilizações quanto a possíveis abusos.

Abordando tal temática, o Supremo Tribunal Federal teve oportunidade de decidir, em caso que se discutia se a divulgação em site oficial dos valores dos vencimentos dos servidores públicos, entre outras informações funcionais, ofenderia ou não os direitos à privacidade e à intimidade, além de poderem colocar em risco a segurança pessoal destes mesmos servidores, que a publicação da remuneração bruta, cargos e funções dos servidores públicos é informação de interesse coletivo ou geral. (STF. Seg.Agr.Reg. S.S. 3.902. São Paulo, itálico nossos)

Neste mesmo caso, o Supremo Tribunal deixou assentado, sintetizando a matéria, que não caberia:

falar de intimidade ou de vida privada, pois os dados objeto da divulgação em causa dizem respeito a agentes públicos enquanto agentes públicos mesmos; [...]. No mais, é o preço que se paga pela opção por uma carreira pública no seio de um Estado republicano. (STF. Seg.Agr.Reg. S.S. 3.902. São Paulo, destaques nossos)

Já quando da paradigmática Arguição de Descumprimento de Preceito Fundamental (ADPF) 130, impetrada pelo Partido Democrático Trabalhista (PDT), visando arguir normas elencadas na Lei Federal no. 5.250/1967, também conhecida como Lei de Imprensa, a qual, ao final, foi considerada, pela maioria dos ministros do Supremo Tribunal, como não recepcionada pela atual ordem constitucional, o STF destacou que a Constituição "destinou à imprensa o direito de controlar e revelar as coisas respeitantes à vida do Estado e da própria sociedade. A imprensa como alternativa à explicação ou versão estatal de tudo que possa repercutir no seio da sociedade [...]". Salientando, a seguir, que "não há liberdade de imprensa pela metade ou sob as tenazes da censura prévia, inclusive a procedente do Poder Judiciário [...]”. (STF.ADPF - 130. Distrito Ferderal.)

\footnotetext{
${ }^{15}$ Exposição de Motivos. Pts. 06 e 24. Disponível em: <http://www.acessoainformacao.gov.br/menu-de-apoio/recursos-passo-apasso/exposicao-motivos-projeto-lei-acesso-informacao.pdf/view>. Acesso em: 22/06/2016.
} 
Em outra passagem, ainda da ADPF 130, o STF, por sua maioria, ao decidir sobre a questão da "proporcionalidade entre liberdade de imprensa e responsabilidade civil por danos morais e materiais", realça um ponto relevante para nossas análises, que é o do risco de que indenizações excessivas operem como inibidores desta liberdade fundamental, ou seja:

Em se tratando de agente público, ainda que injustamente ofendido em sua honra e imagem, subjaz à indenização uma imperiosa cláusula de modicidade. Isto porque todo agente público está sob permanente vigília da cidadania. (STF.ADPF - 130. Distrito Ferderal.)

Observa-se, assim, que em projetos constitucionais, como o brasileiro, a defesa intransigente da transparência e da publicidade da gestão pública, salvo em raras e específicas situações, tem que dar o tom do sentido e âmbito normativo da liberdade de imprensa quando esta, através de suas ações investigativas, problematiza as condutas estatais e dos seus agentes, enquanto membros dos poderes deste Estado.

Percebe-se que, em uma democracia constitucional, remover pesados e persistentes véus da opacidade implica, principalmente quando os questionamentos referem-se ao Estado, a seus poderes, ou a figuras públicas, mais do que combater, formalmente, atos de censura explícitas, pois é necessário reconhecer, por exemplo, que estes mesmos atos podem estar camuflados por detrás de subsídios concedidos a determinados empreendimentos artísticos e culturais, negados os mesmos subsídios àqueles que criticam o establishment.

Deste modo, estes atos de censura podem ocultar-se em pretensões abusivas a direitos quando do exercício e da aplicação de legislações protetivas, assim como naquelas normas que possibilitam discutir danos morais ou direito de resposta diante de matérias vinculadas pela imprensa.

Em poucas palavras, recuperando a força de certos argumentos, já antes postos:

[...] de pouco adiantaria proibir a censura e permitir, pela via da responsabilização ulterior, que as pessoas fossem penalizadas, ou que tivessem que pagar vultosas indenizações pelas suas manifestações causadoras de algum dano a terceiros. (SARMENTO, 2015: 40)

Decorreria destas visões o Estado Democrático de Direito como o lócus da possibilidade, sempre recorrente, de inquirirmos o Estado e seus agentes, de exigirmos que as portas do mesmo sempre permaneçam abertas, que a transparência se converta em dever constitucional, exigência de legitimidade, fonte discursiva de uma governabilidade exposta à luz de uma cidadania que possui o direito fundamental de ser informada por uma imprensa livre. Isto é, liberta de intimidações e censuras implícitas ou indiretas, não irresponsável por abusos, mas também sem receio de, a toda hora, ver-se colocada, por exemplo, diante de demandas criminais ou indenizatórias que podem acabar produzindo aquilo que no contexto estadunidense é denominado de chilling effect ${ }^{16}$, o efeito de frear e esfriar as críticas, mesmo que estas sejam necessárias, não abusivas, constitucionais.

\footnotetext{
${ }^{16}$ Neste sentido, conferir: (YOUN, 2013: 1474-1475).
} 
Neste mesmo diapasão, problematizando a Primeira Emenda ${ }^{17}$, a liberdade de expressão, salienta o professor Frederick Schauer: "The very essence of a chilling effect is an act of deterrence. [ ... ] This can occur not only when activity shielded by the first amendment is implicated, but also when any behavior safeguarded by the Constitution is unduly discouraged". (SCHAUER, 1978: 689-690)

Adentrando mais profundamente no cenário estadunidense, fazemos um recorte que nos conduz a recuperar certos argumentos do célebre caso New York Times Co. v. Sullivan (1964). ${ }^{18}$ Este precedente da Suprema Corte, tido como referência necessária em qualquer estudo a respeito da responsabilização dos meios de comunicação social no exercício da liberdade de imprensa diante de situações que envolvem autoridades e figuras públicas, propõe uma série de argumentos que podem ser extremamente úteis.

Lembremos aqui que, desde o início, já afirmamos que nenhuma liberdade é absoluta, nem mesmo aquelas tidas como fundamentais para o operar de uma democracia constitucional, como é o caso da liberdade de imprensa. Todavia, como estes limites e responsabilizações são implementados, ainda mais quando o assunto versa sobre condutas que envolvem autoridades públicas, é que deve ser problematizado.

Esta necessária problematização é que nos levar a indagar qual seria a mensagem transmitida por um precedente como New York Times Co. v. Sullivan, no qual a Suprema Corte decidiu contra a pretensão levantada por um agente da polícia da cidade de Montgomery, Alabama, que se sentiu difamado por um anúncio publicado pelo movimento de luta pelos direitos civis, no jornal que dá nome ao caso, com algumas incorreções.

Em suma, durante a campanha por direitos civis, levada a cabo por Martin Luther King, um anúncio intitulado "Heed Their Rising Voices" saiu no New York Times com intuito de produzir apoio e arrecadar fundos para o movimento, incluindo a defesa do Doutor King, então à espera do seu julgamento na citada cidade de Montgomery. Neste anúncio, foi informado que em Montgomery, Alabama, estava ocorrendo, por parte da polícia local, uma série de atos de violência contramanifestações pacíficas. Registre-se, também, que, em momento algum, uma pessoa ou autoridade específica foi nomeada.

Contudo, como já dito, após sua publicação, verificou-se que algumas das informações colocadas eram incorretas, errôneas. Em razão desta circunstância, uma autoridade policial da cidade de Montgomery - City Commissioner L. B. Sullivan - decidiu processar o jornal alegando ter sido difamado, haja vista que ele seria um dos responsáveis pelas ações realizadas pela polícia local.

\footnotetext{
${ }^{17}$ First Amendment. Freedom of Religion, Press, Expression. Ratified 12/15/1791. "Congress shall make no law respecting an establishment of religion, or prohibiting the free exercise thereof; or abridging the freedom of speech, or of the press; or the right of the people peaceably to assemble, and to petition the Government for a redress of grievances".

${ }^{18}$ Neste momento, aproveita-se para indicar que os precedentes mencionados, oriundos da Suprema Corte dos Estados Unidos, a partir deste ponto, possuem como fonte o banco de dados dos sites da Cornell University Law School (Legal Information Institute) <http://www.law.cornell.edu/supct/cases/topics/tog_freedom_of_speech.html>, do United States Supreme Court Center, <http://supreme.justia.com>, além do <http://www.oyez.org>, referente ao The Oyez Project, salvo quando abordados diretamente por “terceiros". Já as decisões do Supremo Tribunal Federal e do Superior Tribunal de Justiça, que aqui são abordadas, vol.10, nº.01, Rio de Janeiro, 2017.pp. 219-240 226
} 
Condenado a pagar uma indenização vultosa nas instâncias de Alabama, o NYT apelou para a Suprema Corte, alegando, grosso modo, que o jornal não tinha tido nenhuma intenção de difamar o oficial da polícia, tanto que nenhum nome constava do referido anúncio, além de enfatizar a necessidade de crítica livre que a imprensa precisa deter para servir à democracia.

Em uma decisão histórica, a Suprema Corte, de modo unânime, deu ganho de causa ao apelo do jornal, anotando que, quando um caso de possível difamação envolvesse um "public official", um agente público, o ônus da prova seria invertido, pois este teria que comprovar que a imprensa agiu com "actual malice", expressa má-fé, e negligência diante das informações, sabidamente não verídicas, veiculadas.

Como escreve Owen Fiss, em Sullivan, a Suprema Corte “[...] limitou o poder de oficiais públicos de receber indenizações em ações de difamação", impondo a estes oficiais, caso entendam que sofreram danos pelas informações a respeito de suas ações funcionais, o ônus de provar "[...] que aquelas afirmações foram publicadas ou transmitidas com conhecimento ou grave negligência (reckless disregard) sobre a sua falsidade". (FISS, 2005:100)

Nos termos da própria Suprema Corte, há a necessidade, diante de pretensões indenizatórias relativas a "officials conducts", dos atingidos provarem a existência da citada "actual malice", isto é: "[...] that the statement was made with knowledge of its falsity or with reckless disregard of whether it was true or false. (New York Times Co.v. Sullivan, 1964)

Denota-se, em vários momentos, que a ênfase recai na possibilidade de crítica ao estabelecido, ao modo como os agentes públicos e suas condutas são passíveis de serem questionados pela cidadania e pela imprensa. Isto é, as liberdades de expressão e de imprensa como instrumentos de potencializar os debates e as discussões públicas, operando pública e criticamente, principalmente diante de quadros públicos.

Nesta linha, o Juiz Black salientou que "to punish the exercise of this right to discuss public affairs or to penalize it through libel judgments is to abridge or shut off discussion of the very kind most needed", para logo depois completar que duvidava que "[ $\ldots]$ a country can live in freedom where its people can be made to suffer physically or financially for criticizing their government, its actions, or its officials". (Concurring Opinion - New York Times Co. v. Sullivan, 1964)

Porém, a passagem que marcou este precedente foi escrita pelo lembrado Juiz Brennan, o qual construiu um argumento que se transformou em verdadeira máxima interpretativa da liberdade de expressão e de imprensa nos Estados Unidos, qual seja:

we consider this case against the background of a profound national commitment to the principle that debate on public issues should be uninhibited, robust, and wide-open, and that it may well include vehement, caustic, and sometimes unpleasantly sharp attacks on government and public officials. (New York Times Co.v. Sullivan, 1964, destaques nossos) 
Aqui, devemos fazer um rápido, mas necessário parêntesis. Comprometer-se com um espaço público de debates como o exposto por Brennan é basilar em uma democracia constitucional que se considera pluralista e transparente, mas isto não significa desconsiderarmos a história subjacente a estes mesmos espaços de debates, ou seja, devemos nos perguntar também como o acesso a este espaço "robusto" tem ocorrido ou sido conformado historicamente.

Com esta ressalva, podemos continuar e afirmar que a decisão da Suprema Corte em Sullivan dificulta, senão, impede, que jornais sejam condenados por difamação (libel) contra autoridades públicas, isto é, críticas, ainda que ácidas e duras, de agentes públicos, como que passaram a serem cobertas pela proteção conferida pela Primeira Emenda.

Owen Fiss destaca que, "em New York Times v. Sullivan, a Corte restringiu a capacidade estatal de proteger a reputação, mas, de fato, o interesse reputacional em risco era de agentes públicos, que, na visão da Corte, necessariamente assumiram certos riscos à sua reputação quando adentraram a arena política”. (FISS, 2005: 36)

Em outras palavras, autoridades públicas, em razão de sua própria atividade, de suas funções, devem saber que poderão, a qualquer momento, serem questionados e criticados vigorosamente, e que isto faz parte do cenário em que eles escolheram, por sua livre vontade, atuar.

Demonstra-se, claramente, que em New York Times Co. v. Sullivan (1964), a Suprema Corte dos Estados Unidos decidiu que autoridades públicas estariam mais sujeitas a críticas, mesmo que pesadas, por parte dos órgãos de imprensa, do que outros cidadãos, fixando-se um padrão, o qual ainda norteia a aplicação da First Amendment em contextos envolvendo o papel do jornalismo diante de condutas e atos dos "government and public officials". Estes, como já exposto, para terem direito à proteção contra ilegítimas, difamatórias e abusivas reportagens, devem provar que as mesmas foram realizadas com efetiva e expressa má-fé (actual malice), ou temerária, negligente e inescusável imprudência quanto à veracidade ou falsidade do conteúdo da matéria publicada (reckless disregard of whether it was true or false).

Assim, a Supreme Court procurou garantir o mais amplo exercício da liberdade da imprensa diante destas autoridades públicas, consubstanciando um direito fundamental à crítica e ao poder investigativo dos meios de comunicação social, como um imperativo democrático.

Em termos mais diretos, nas palavras da própria Supreme Court: "Factual error, content defamatory of official reputation, or both, are insufficient to warrant an award of damages for false statements unless "actual malice" -- knowledge that statements are false or in reckless disregard of the truth -- is alleged and proved". (New York Times Co. v. Sullivan, 1964)

Este ponto fica ainda mais nítido em outra passagem marcante do voto do Justice William Brennan, encarregado que foi de escrever a opinião daquela Corte, quando recupera argumento por ele mesmo apontado 
em outro caso ${ }^{19}:$ " $[\ldots]$ erroneous statement is inevitable in free debate, and that it must be protected if the freedoms of expression are to have the 'breathing space' that the 'need to ... survive'." (New York Times Co. v. Sullivan, 1964, destaques nossos).

Ou seja, a liberdade de expressão e de imprensa precisam de ar livre para poderem cumprir, adequadamente, seus relevantes papéis constitucionais, tanto aqueles de informar e fazer circular as ideias e pensamentos, como também os de averiguar, investigar, denunciar e problematizar condutas e temas de pauta pública.

Deste modo, também trabalhando alguns destes pontos, Gustavo Binenbojm bem resume o impacto de New York Times Co. v. Sullivan para "o exercício do autogoverno", pois "tal standard foi fixado pela Suprema Corte com o declarado propósito de criar um espaço no qual os órgãos de imprensa pudessem "respirar" (breathing space), sem o risco de serem calados por ameaças de agentes públicos". (BINENBOJM, 2003: 372)

Como Ronald Dworkin salienta, ao escrever sobre o mesmo caso Sullivan, a:

decisão da Corte liberou a imprensa para fazer investigações e publicar reportagens sem o medo "paralisante" de que um júri pudesse aproveitar um erro factual ou um lapso jornalístico para determinar uma indenização por calúnia e difamação que levasse à bancarrota o órgão de imprensa em questão (DWORKIN, 2006: 312).

É interessante observarmos que algumas destas posições sobre a centralidade da liberdade de expressão e de imprensa poderem operar sem medo, o que não implica imunidade absoluta, mas sim o estabelecimento de critérios estritos de responsabilizações, principalmente quando as opiniões e matérias envolvam autoridades públicas, não se originam em Sullivan, podendo ser encontradas, ainda que pontualmente, em casos passados. ${ }^{20}$

Além disso, estas posições foram, de certo modo, ampliadas, passando a incluir não apenas agentes públicos, mas também "public figures", figuras públicas, reforçando a possibilidade de crítica pública, inclusive aquelas que possam produzir profundo sofrimento emocional ("emotional distress").

Estas assertivas são visíveis em outro paradigmático case, o qual envolveu a publicação de uma charge, tida, por muitos, como extremamente ofensiva à honra de seu destinatário. As questões implicadas nestas assertivas acabaram desaguando na Suprema Corte e, em Hustler Magazine, Inc. v. Falwell, de 1988, na qual, por exemplo, podemos ler:

In order to protect the free flow of ideas and opinions on matters of public interest and concern, the First and Fourteenth Amendments prohibit public figures and public officials from recovering damages for the tort of intentional infliction of emotional distress by reason of the publication of a caricature such as the ad parody at issue without showing in addition that the publication contains a false statement of fact which was made with "actual malice," i.e., with knowledge that the statement was false or with reckless disregard as to whether or not it was true. (Hustler Magazine, Inc. v. Falwell, 1988)

Por fim, percebe-se, em Hustler Magazine, que a Suprema Corte, em profundo diálogo com Sullivan,

\footnotetext{
${ }^{19}$ Ver: NAACP v. Button, 1963.

${ }^{20}$ Ver, entre outros: (Baumgartner v. United States, 1944).
} 
resume muito do nosso caminho até aqui quando destaca:

Of course, this does not mean that any speech about a public figure is immune from sanction in the form of damages. Since New York Times Co. v. Sullivan, 376 U. S. 254 (1964), we have consistently ruled that a public figure may hold a speaker liable for the damage to reputation caused by publication of a defamatory falsehood, but only if the statement was made "with knowledge that it was false or with reckless disregard of whether it was false or not". (Hustler Magazine, Inc. v. Falwell, 1988, destaques nossos)

\section{LIMITES: CONDIÇÃO DE POSSIBILIDADE}

Ainda nos movendo pelo mesmo caso Hustler, recuperando e reforçando a metáfora do "espaço para respirar" que as liberdades fundamentais exigem, lemos que:

Freedoms of expression require "breathing space." [... ]. This breathing space is provided by a constitutional rule that allows public figures to recover for libel or defamation only when they can prove both that the statement was false and that the statement was made with the requisite level of culpability. (Hustler Magazine, Inc. v. Falwell, 1988)

Ora, nesta passagem, entre outras acima colecionadas, podemos verificar que este verdadeiro imperativo constitucional de um amplo espaço para respirar, que a liberdade imprensa em um Estado Democrático de Direito possui, não pode ser traduzido como se fosse sinônimo de uma cobertura protetiva para atos de má-fé, de omissão quanto à busca de fontes fidedignas que embasem os textos e matérias jornalísticas, de investigações apressadas e sem fundamentos, ou seja, liberdade de imprensa é crítica informativa, não manipulação ou desvirtuação das narrativas dos fatos a serem publicados.

Este é um ponto que deve ser sempre marcado, não há uma liberdade de imprensa ilimitada, pensemos, por exemplo, nos discursos de ódio e de apologia da violência contra este ou aquele grupo social. O próprio direito constitucional de resposta $\left(\operatorname{art} .5^{\circ}, \mathrm{V}\right)^{21}$ revela que há limites, que a liberdade de imprensa não cobre pretensões abusivas, que estas, quando comprovadas, podem e devem ser responsabilizadas.

Em outras palavras, a imprensa tem o papel central de investigar e apurar atos contrários ao direito, principalmente quando estes dizem respeito à implementação de políticas públicas ou atos de autoridades dos poderes do Estado, pois, do contrário, casos como o tristemente célebre Escola Base, ocorrido em São Paulo no ano de 1994, fruto de precipitações e negligências dos órgãos de imprensa no processo de apurar os fatos, poderão voltar a ocorrer. ${ }^{22}$

Nessa linha, lembramo-nos de um importante documento internacional sobre liberdade de expressão e de imprensa, por coincidência também do ano de 1994, que é a importante Declaração de Chapultepec, a qual destaca que "a credibilidade da imprensa está ligada ao compromisso com a verdade, à busca de precisão,

\footnotetext{
${ }^{21}$ Conferir, também: Lei 13.188, de 11 de novembro de 2015, que "dispóe sobre o direito de resposta ou retificação do ofendido em matéria divulgada, publicada ou transmitida por veículo de comunicação social”.

${ }^{22}$ Sobre este infeliz exemplo, ver: <http://wwwl.folha.uol.com.br/cotidiano/2014/03/1432195-imprensa-amadureceu-apos-ocaso-escola-base-aponta-debate.shtml>. Acesso em: 28/06/2016.
} 
imparcialidade e equidade e à clara diferenciação entre as mensagens jornalísticas e às comerciais" ${ }^{23}$

Esta tensão entre liberdade e seus possíveis limites, constitutiva de qualquer democracia constitucional, pôde ser vista na já lembrada ADPF 130, na qual o Ministro Celso de Melo, não obstante, em várias passagens, enfatizar a "qualificação constitucional" das "críticas jornalísticas", principalmente quando dirigidas "ás autoridades e aos agentes do Estado", ou "figuras públicas, com alto grau de responsabilidade na condução dos negócios do Estado", desvelando seu enorme papel em nosso Estado Democrático de Direito, em que restrições devem ser exceções também constitucionais, escreve:

é certo que o direito de crítica não assume caráter absoluto, eis que inexistem, em nosso sistema constitucional, como reiteradamente proclamado por esta Suprema Corte [...], direitos e garantias revestidos de natureza absoluta. (STF.ADPF - 130. Distrito Ferderal.)

Nesta mesma linha argumentativa, temos também vários julgados do Superior Tribunal de Justiça (STJ), in verbis:

O direito à informação não elimina as garantias individuais, porém encontra nelas os seus limites, devendo atentar ao dever de veracidade, ao qual estão vinculados os órgãos de imprensa, pois a falsidade dos dados divulgados manipula em vez de formar a opinião pública, bem como ao interesse público, pois nem toda informação verdadeira é relevante para o convívio em sociedade. (STJ. REsp. 1414004. Distrito Federal.)

Tais argumentos levantam a questão sobre publicações precipitadas, denúncias sem qualquer fundamento, apenas midiáticas, espetacularização que desinforma, isto é, desvelam que se o espaço da liberdade de imprensa deve ser pleno oxigênio, o mesmo não é imune a problematizações e responsabilizações - não censura - sobre o modo como a imprensa opera em democracias constitucionais.

Entretanto, podemos identificar, junto a estas assertivas, o predomínio da noção de que a liberdade de imprensa não pode ser julgada e condenada por qualquer erro ou falta de objetividade, haja vista que esta liberdade não se move pelo campo das ciências exatas, exigindo-se que se guie pela busca de fontes seguras dos fatos que irão ser narrados, pela maior exatidão possível durante os trabalhos de investigação jornalística, de ouvir os dois lados, mas que isto não signifique que só verdades absolutas sejam noticiadas, pois isto seria uma contradição com o papel de crítica, esperado, ainda mais quando esta volta-se ao Estado e suas autoridades.

Recuperando outro ponto da mesma decisão do STJ, acima citada, temos:

O veículo de comunicação somente se exime de culpa quando buscar fontes fidedignas, exercendo atividade investigativa, ouvindo as diversas partes interessadas e afastando quaisquer dúvidas sérias quanto à verossimilhança do que divulgará. (STJ. REsp. 1414004. Distrito Federal.)

No mesmo STJ, encontramos:

O jornalista tem um dever investigar os fatos que deseja publicar. Isso não significa que sua cognição deva ser plena e exauriente à semelhança daquilo que ocorre em juízo. [...]. Isso se dá, em primeiro lugar, porque os meios comunicação, como qualquer outro particular, não

23 Ponto IX. Disponível em: <http://www.direitoshumanos.usp.br/index.php/Documentos-n\%C3\%A3o-Inseridos-nasDelibera\%C3\%A7\%C3\%B5es-da-ONU/declaracao-de-chapultepec-1994.html >. Acesso em: 24/06/2016. 
detém poderes estatais para empreender tal cognição. Ademais, impor tal exigência à significaria engessá-la e condená-la a morte. (STJ. Resp. 984803. Espírito Santo.)

Este posicionamento fica ainda mais claro quando lemos, em outro julgado do citado Superior Tribunal de Justiça, que, não obstante não se exigir "prova inequívoca da má-fé da publicação ("actual malice"), para ensejar a indenização", nem se permitir "a leviandade por parte da e a publicação informações absolutamente inverídicas que possam atingir a honra da pessoa", isto não significa que:

o dever ao qual estão vinculados os órgãos não deve consubstanciar-se dogma absoluto, ou condição peremptoriamente necessária à mas um compromisso ético com a informação verossímil, o que pode, eventualmente, abarcar informações não totalmente precisas. (STJ. Resp. 680794. Paraná.)

Em outras palavras, como anota o já lembrado Ministro Celso de Mello, ao dialogar com o Tribunal Europeu de Direitos Humanos (TEDH): "[...] a limitação do direito à informação e do direito (dever) de informar, mediante (inadmissível) redução de sua prática "ao relato puro, objetivo e asséptico de fatos, não se mostra constitucionalmente aceitável nem compatível com o pluralismo" [...]”. (STF. ADPF - 130. Distrito Ferderal.)

Sendo assim, visualizamos que as excepcionais restrições e limites impostos, por exemplo, pelo Poder Judiciário à liberdade de imprensa, devem apresentar-se, nas situações específicas de aplicação, como necessários ao próprio operar da democracia constitucional, não como resultantes de interesses privados ou corporativos. Isto é, qualquer responsabilização deve funcionar, simultaneamente, como condição de possibilidade, pois, se isto não ocorrer, teremos, em realidade, censuras indiretas travestidas de pretensões à direitos e garantias.

Deste modo, como bem adverte Daniel Sarmento, salientar a importância de que qualquer afirmação veiculada pela imprensa deva passar por apurações criteriosas, cuidadosas e rigorosas, não pode significar, por exemplo, fecharmos a "esfera pública de debates" a temas ainda controversos, abertos, desvelando, assim, que

[...] o dever de veracidade não pode significar a obrigação de só divulgar fatos incontroversos, nem tampouco importa na responsabilidade incondicional dos que transmitirem informações porventura incorretas. Tal dever, na verdade, se esgota na exigência de lealdade e diligência dos que comunicam informações, que não podem difundir fatos que saibam inverídicos, nem fazê-lo sem qualquer esforço para apurar a sua veracidade. (SARMENTO, 2015: 09) $)^{24}$

A partir de todas estas considerações e assertivas, visualizamos que a liberdade de expressão e sua inseparável companheira, a liberdade de imprensa, não obstante possíveis limites e responsabilizações, revelam ser ferramentas necessárias para que, em democracias constitucionais, o ambiente seja desembaçado, fazendo com que as névoas que cobrem certas atividades do Estado e de seus agentes, seja levantada, e a visibilidade e transparência possam predominar.

Dialogando com o contexto estadunidense, diríamos que a posição preferencial ${ }^{25}$ destas liberdades

\footnotetext{
${ }^{24}$ Sobre este tópico, também ver: (FARIAS, 1996).

${ }^{25}$ Esta posição preferencial das liberdades fundamentais, garantidas pela Primeira Emenda, é explicitada no cenário dos Estados Unidos em decisões da Suprema Corte daquele país, como, por exemplo, Thomas v. Collins (1945), em que podemos ler vol.10, nº. 01, Rio de Janeiro, 2017. pp. 219-240 
fundamentais enfatiza aquilo que Toby Mendel, em profícua análise, a partir do direito comparado, da denominada liberdade de informação, denomina de "princípio da máxima divulgação", o qual implica que as informações devem poder ser amplamente conhecidas e com alto grau de acessibilidade, imperando um "sistema estrito de exceções”, ou seja, estas "[...] exceções devem ser clara e restritamente definidas e sujeitas a rigorosos testes de "dano" e "interesse público"." (MENDEL, 2009: 32-34; 36-38)

\section{CONSIDERAÇÕES FINAIS}

De tudo o exposto, desvela-se o potencial que uma imprensa não intimidada, livre, possui de afastar as sombras que sempre gravitam em torno dos poderes do Estado que, inclusive, possibilita averiguarmos, por exemplo, se as responsabilizações, os limites, estão sendo aplicados como reflexo e possibilidade das próprias práticas e compromissos constitucionais ou, ao inverso, procuram edificar "muros de censuras", ainda que construídos nas entrelinhas de pretensões a direitos. Isto é, esta negação da crítica dissolvente através de uma liberdade como a da imprensa, conforma uma "bebida amarga", para nos apropriarmos da poética letra da música Cálice, de Chico Buarque e Gilberto Gil, ela própria, uma verdadeira apologia da liberdade de expressão, do direito de informar e ser informado, com transparência e responsabilidade, sendo esta ainda a maior garantia que podemos ter de não vermos, novamente, "emergir o monstro da lagoa".

Dito de outro modo, a defesa de uma liberdade de imprensa, pluralista e crítica, é um ponto central a qualquer processo democrático, haja vista a sempre possível presença de armadilhas normativas em democracias constitucionais, sendo o risco de abuso das garantias e direitos fundamentais algo que não pode ser completamente eliminado.

Liberdade de imprensa que, principalmente, diante do Estado, de suas autoridades, tem o papel de informar, com responsabilidade, mas também sem o receio de ser confrontada, judicialmente, toda vez que alguma de suas ações investigativas desagradar esta dimensão do público, ou seja, requer-se, como acima vimos, uma dose maior de proteção jurídica qualificada, de critérios objetivos de responsabilização, pois, só assim, poderá atuar, autônoma e independentemente, como instrumento de checar não só a legalidade das decisões políticas e jurídicas, mas também do grau de legitimação destas.

Esta função de constantemente checar, de providenciar a maior exposição possível do Estado, de suas autoridades e servidores, ao sol da crítica, é o que a doutrina estadunidense denomina de watchdog function, a função de cão de guarda. Isto é, "[...] more precisely the watchdog role consists in being a "check" against abuse by

argumentos que afirmam: "the preferred position of the freedoms secured by the First Amendment" "the preferred place given in our scheme to the great, the indispensable, democratic freedoms secured by the First Amendment" (Thomas v. Collins, 1945). Assim como também em Branzburg v. Hayes (1972), no qual o Juiz Douglas, em famoso voto divergente, escreveu: "The press has a preferred position in our constitutional scheme not to enable it to make money, not to set newsmen apart as a favored class, but to vol.10, no. 01, Rio de Janeiro, 2017. pp. 219-240 
government [...]”. (BAKER, 2007: 05)

Este cão de guarda, para poder atentamente vigiar e dar o alarme, quando o Estado e seus membros agem ilegal ou ilegitimamente, precisa de amplos espaços para bem respirar (breathing spaces), fazendo com que qualquer restrição a estes espaços seja excepcional, rara, além de exigir profundos, concretos e exaustivos fundamentos que justifiquem, publicamente, a sua imposição.

Desta maneira, esta tradução da liberdade de imprensa como um cão de guarda que está sempre a desconfiar daquilo que é opaco, pouco transparente, ainda mais quando esta opacidade advém do Estado, é central para tornar pauta pública de debates uma série de temas que muitos prefeririam que continuassem sem ser problematizados, como, por exemplo, assuntos referentes a aborto, eutanásia, corrupção, financiamento privado de campanhas eleitorais, ou sobre alguns desníveis remuneratórios de certas categorias de servidores públicos e membros dos poderes constituídos.

Aqui, apropriando-nos do pensamento de um estudioso da liberdade de expressão e de imprensa nos Estados Unidos, Rodney Smolla, reconhecemos e admitimos que nos movemos por um período da história em que "[...] the watchdog role of a free and aggressive press is more vital than ever." (SMOLLA, 2008: 1430) ${ }^{26}$.

Este papel questionador e desconstrutivo que a imprensa, em um Estado Democrático de Direito, deve representar, ainda mais na presença de autoridades e figuras públicas ${ }^{27}$, quando seus atos se revestem de interesse coletivo e social, não implica, como já realçamos antes, imunização, mas sim a emergência de um campo protetivo diferenciado, em razão desta liberdade fundamental necessitar de espaços maiores de oxigenação. Isto é, limites não para conter esta função investigativa e de crítica, mas, sim, para legitimá-la ainda mais, em que ser agressiva não é o mesmo que desmedida. ${ }^{28}$

Em breves palavras, a proteção à liberdade investigativa da imprensa é a regra em democracias constitucionais, sendo as restrições, diretas e indiretas, exceções sujeitas a fundamentações e justificativas mais contundentes. Como afirma o pensamento constitucional estadunidense, qualquer limite a esta liberdade deve passar por escrutínios constitucionais mais estreitos ${ }^{29}$, ainda mais quando o objeto das reportagens e noticiários é o agir de autoridades públicas.

Denota-se, assim, por exemplo, que autoridades públicas e agentes políticos, em razão de seus atos

bring fulfillment to the public's right to know". Ver, também: (SAMPAIO, 2002: 750-755).

${ }^{26}$ Conferir, também: (CALVERT; TORRES, 2011).

${ }^{27}$ Em relação a temática envolvendo figuras e personalidades públicas, conferir: (STF. ADI - 4815. Distrito Federal). Ver, principalmente, o voto do Ministro Luis Roberto Barroso. Nesta ação direta, o Supremo Tribunal Federal, por unanimidade, entendeu não ser necessária qualquer autorização prévia para a publicação das chamadas biografias não autorizadas. Este ponto, também merece ser analisado na perspectiva da Supreme Court dos EUA, tanto nos casos Curtis Publishing. Co. v. Butts (1967) e Gertz v. Robert Welch, Inc. (1974), quanto na acima citada decisão, Hustler Magazine, Inc. v. Falwell(1988).

${ }^{28}$ Como nos lembra Eliamara Fontoura Brun, "a rápida produção em escala das notícias pode ocasionar erros na precisão das informações e uma precipitação no julgamento do ocorrido”. (BRUN, 2011)

${ }^{29}$ Conferir: (BUNCHAFT; FREITAS; HAASIS, 2011) e (SIEGEL, 2006). 
funcionais, seus deveres e direitos, têm, prima facie, um âmbito de privacidade diverso daquele que conforma a esfera dos cidadãos comuns, já que, como acima já explicitado, este seria o custo pela escolha de servir ao público, ou seja, a transparência no trato de temas de interesse público impõe uma superexposição ao sol e aos olhares de uma imprensa cão de guarda. ${ }^{30}$

Nesta mesma trilha argumentativa é que podemos compreender o porquê da Declaração de Princípios sobre Liberdade de Expressão, aprovada, no ano 2000, pela Comissão Interamericana de Direitos Humanos, ressaltar, entre outros pontos, que "os funcionários públicos estão sujeitos a maior escrutínio da sociedade. As leis que punem a expressão ofensiva contra funcionários públicos, geralmente conhecidas como "leis de desacato", atentam contra a liberdade de expressão e o direito à informação". ${ }^{31}$

Em termos outros, como podemos ler em breve passagem de um texto da Organização NãoGovernamental Article 1932, voltada à defesa da liberdade de expressão e de imprensa no mundo, intitulado Public's right to know, temos que:

Information is the oxygen of democracy. If people do not know what is happening in their society, if the actions of those who rule them are hidden, then they cannot take a meaningful part in the affairs of that society. But information is not just a necessity for people - it is an essential part of good government. Bad government needs secrecy to survive. It allows inefficiency, wastefulness and corruption to thrive. ${ }^{33}$

Para finalizar, baseando-nos em todas as considerações aqui colocadas, as quais serviram para reforçar a centralidade da liberdade de imprensa numa democracia constitucional, não podemos nos furtar, neste momento, em dizer da necessidade de fomento a uma base plural dos meios de comunicação social, pois esta amplia o olhar e o olfato deste cão de guarda, o qual não é imune de ser responsabilizado quando atacar sem evidências fidedignas ou com dados coletados negligentemente, ou quando manipular e desinformar. Contudo, o maior risco que este watchdog corre, nos dias atuais, é de ser domesticado, de investigar apenas estereótipos, de ser seletivo e de silenciar-se diante de certos atores sociais mais poderosos e influentes na esfera pública, adestramento este, diga-se, passível de ocorrer não apenas através das mãos do aparato estatal, mas também pelos seus próprios donos e proprietários, mas esta já é outra história.

\footnotetext{
${ }^{30}$ Mas, sempre com a importante ressalva que: "A mídia quando se afasta da concepção Watchdog, se afasta da sua responsabilidade social e glorifica o seu lado mais pernicioso: a instauração de tribunais paralelos”. (BRUN, 2011).

31 Disponível em: <http://www.cidh.oas.org/basicos/portugues/s.convencaolibertade.de.expressao.htm>. Acesso em: 24/06/2016.

${ }^{32}$ Tal nome é referência direta ao artigo 19, da Declaração Universal dos Direitos Humanos, de 1948, da Organização das Nações Unidas, na qual se lê: "Todo ser humano tem direito à liberdade de opinião e expressão; este direito inclui a liberdade de, sem interferência, ter opiniōes e de procurar, receber e transmitir informações e ideias por quaisquer meios e independentemente de fronteiras." Disponível em: <http://unesdoc.unesco.org/images/0013/001394/139423por.pdf>. Acesso em: 27/06/2016.
} 


\title{
FREEDOM OF THE PRESS AND PUBLIC AUTHORITIES: NOTES FROM THE DEMOCRATIC CONSTITUTIONAL STATE
}

\begin{abstract}
This paper intends to discuss the freedom of the press, its role and its limits, from the paradigm of the Democratic Constitutional State, in which the requirement of transparency and publicity is a true constitutional imperative in the conduction of actions and public policies. The discussion focuses on the relationship between the investigative role of the press in relation to the so-called public authorities. Hence, it explores if these authorities would have the same relationship with the freedom of the press than other citizens, when subjects that gravitate around their roles and responsibilities are taken into account. For this purpose, keeping in mind our own constitutional context, we decided to use Comparative Law, focusing on decisions of the Supreme Court of the United States that deal with the same issue addressed here. It concludes that freedom of the press has an essential and constitutionally recognized role in the Democratic Constitutional State.
\end{abstract}

Keywords: Freedom of the Press; Limits; Public Authorities; Democratic Constitutional State.

\section{REFERÊNCIAS BIBLIOGRÁFICAS}

BAKER, C. Edwin. Media Concentration and Democracy - Why Ownership Matters. Cambridge: Cambridge University Press, 2007.

"Viewpoint Diversity and Media Ownership". In: Federal Communications Law Journal. Vol. 61. No.3. 2009, pp. 651-672. Disponível em: <http://www.repository.law.indiana.edu/fclj/vol61/iss3/5/>. Acesso em: $27 / 06 / 2016$.

BINENBOJM, Gustavo. "Meios de Comunicação de Massa, Pluralismo e Democracia Deliberativa: As liberdades de expressão e de imprensa nos Estados Unidos e no Brasil”. In. Revista da EMERJ, Vol. 6 n.23, 2003, pp. 360-380. Disponível em: < http://www.emerj.tji.j.jus.br/revistaemerj_online/edicoes/revista23/revista23_360.pdf>. Acesso em: $02 / 06 / 2016$.

BOBBIO, Norberto. O Futuro da Democracia: uma defesa das regras do jogo. 10a.ed. Trad. Marco Aurélio Nogueira. São Paulo: Paz e Terra, 2006.

BRANDEIS, Louis D. “What publicity can do”. In: Harper’s Weekly. December. 20. 1913. pp. 10-13. Disponível em: $<$ http://3197d6d14b5f19f2f4405e13d29c4c016cf96cbbfd197c579b45.r81.cf1.rackcdn.com/collection/papers/1910/1913_12_20_What_Pu blicity_Ca.pdf>. Acesso em: 01/06/2016.

BRASIL. Constituição da República Federativa do Brasil (1988). Disponível em: < http://www.planalto.gov.br/ccivil_03/constituicao/constituicaocompilado.htm>. Acesso em: 02/06/2016.

Lei 12.527, de 18 de novembro de 2011. Exposição de Motivos. Pontos 06 e 24. Disponível em: <http://www.acessoainformacao.gov.br/menu-de-apoio/recursos-passo-a-passo/exposicao-motivos-projeto-leiacesso-informacao.pdf/view>. Acesso em: 22/06/2016.

${ }^{33}$ Disponível em: <https://www.article19.org/resources.php/resource/1797/en/>. Acesso em: 28/06/2016. vol.10, nº. 01, Rio de Janeiro, 2017. pp. 219-240 
Lei 13.188, de 11 de novembro de 2015. Dispõe sobre o direito de resposta ou retificação do ofendido em matéria divulgada, publicada ou transmitida por veículo de comunicação social. Disponível em: <http://www.planalto.gov.br/ccivil_03/_Ato2015-2018/2015/Lei/L13188.htm>. Acesso em: 01/06/2016.

STF. Arguição de Descumprimento Fundamental (ADPF). 130. Distrito Federal. Relator: Ministro Carlos Ayres Britto. 2009.

STF. Segundo Ag.Reg. na Suspensão de Segurança. 3.902 (SS 3.902 AgR-Segundo). São Paulo. Relator: Ministro Carlo Ayres Britto (Vice-Presidente). 2011. Lúcia. 2015

STF. Ação Direta de Inconstitucionalidade (ADI) 4.815. Distrito Federal. Relatora: Ministra Cármen

STF. Agravo Regimental na Reclamação 23.889 (RCL 23.889 AGR/PR). Paraná. Relatora: Ministra Rosa Weber. 2016.

STJ. Recurso Especial. 984803. 3ª. Turma. Espírito Santo. Relatora: Ministra Nancy Andrighi. 2009.

STJ. Recurso Especial. 680794. 4a. Turma. Paraná. Relator: Ministro Luis Felipe Salomão. 2010.

STJ. Recurso Especial. 1414004. 3a. Turma. Distrito Federal. Relatora: Ministra Nancy Andrighi. 2014.

BRUN, Eliamara Fontoura. "O cão de guarda da sociedade”. In: Observatório da Imprensa. Diretório Acadêmico. Jornalismo de Investigação. Edição n. 633. 15 março 2011. Disponível em: $<$ http://observatoriodaimprensa.com.br/diretorio-academico/o-cao-de-guarda-da-sociedade/>. Acesso em: 18/06/2016.

BUNCHAFT, Maria Eugenia; FREITAS, Beatriz Ferreira de; HAASIS, Christiane de Carvalho. "A Equal Protection e a discriminação por orientação sexual na jurisprudência da Suprema Corte Norte-Americana”. In: Revista da Faculdade de Direito da UFG, Vol.35, n. 1, jan./jun. 201 1, pp. $41-59$.

CALVERT, Clay; TORRES, Mirelis. "Putting the Shock Value in First Amendment Jurisprudence: When Freedom for the Citizen-Journalist Watchdog Trumps the Right of Informational Privacy on the Internet". In: Vanderbilt J. Of Ent. And Tech. Law. Vol. 13:2. 2011, pp. 323-355. Disponível em: <http://www.jetlaw.org/wpcontent/uploads/2011/05/Calvert-FINAL.pdf $>$. Acesso em: 04/06/2016.

CARAZZAI, Estelita Hass. Magistrados entram com dezenas de ações contra jornalistas no PR. Folha de São Paulo. 07 junho 2016. Disponível em: <http://wwwl.folha.uol.com.br/poder/2016/06/1778916-magistradosentram-com-dezenas-de-acoes-contra-jornalistas-no-pr.shtml>. Acessos em: 10/06/2016.

CARVALHO FILHO, José dos Santos. Manual de Direito Administrativo. 27a. ed. São Paulo: Editora Atlas, 2014.

CASO 'ESCOLA BASE'. Folha de São Paulo. Disponível em: $<$ http://wwwl.folha.uol.com.br/cotidiano/2014/03/1432195-imprensa-amadureceu-apos-o-caso-escola-baseaponta-debate.shtml>. Acesso em: 28/06/2016.

CORNELL UNIVERSITY. Portal Legal Information Institute. Disponível em: $<$ http://www.law.cornell.edu/supct/cases/topics/tog_freedom_of_speech.html>. Último Acesso em: 28/06/2016.

DA REDAÇÃO. Editorial. As instituições e a liberdade de imprensa. Gazeta do Povo. 11 junho 2016. Disponível em: $\quad$ http://www.gazetadopovo.com.br/opiniao/editoriais/as-instituicoes-e-a-liberdade-de-imprensae7o0uel0612t82egy0qmsiuyg>. Acesso em: 12/06/2016. 
Debate público e respeito às instituições. Gazeta do Povo. 23 fevereiro 2016. Disponível em: $\overline{<h t t p: / / w w w . g a z e t a d o p o v o . c o m . b r / o p i n i a o / e d i t o r i a i s / d e b a t e-p u b l i c o-e-r e s p e i t o-a s-i n s t i t u i c o e s-~}$ 88wdg4xlz23gdp632ntbzr7um>. Acesso em: 22/06/2016.

Jornalistas que divulgaram salários de magistrados são alvos de ações. Portal G1.Globo.com. 07 junho 2016. Disponível em: <http://gl.globo.com/pr/parana/noticia/2016/06/jornalistas-que-divulgaram-salariosde-magistrados-sao-alvos-de-acoes.html>. Acesso 10/06/2016.

DECLARAÇÃO DE PRINCÍPIOS SOBRE LIBERDADE DE EXPRESSÃO. Comissão Interamericana de

Direitos Humanos. $2000 . \quad$ Disponível em:
<http://www.cidh.oas.org/basicos/portugues/s.convencao.libertade.de.expressao.htm>. Acesso em: $24 / 06 / 2016$

DECLARAÇÃO UNIVERSAL DOS DIREITOS HUMANOS. Organização das Nações Unidas (ONU). 1948. Disponível em: <http://unesdoc.unesco.org/images/0013/001394/139423por.pdf>. Acesso em: $27 / 06 / 2016$.

DECLARAÇÃO DE CHAPULTEPEC. Sociedade Interamericana de Imprensa. 1994. Disponível em: $<$ http://www.direitoshumanos.usp.br/index.php/Documentos-n\%C3\%A3o-Inseridos-nas-

Delibera\%C3\%A7\%C3\%B5es-da-ONU/declaracao-de-chapultepec-1994.html>. Acesso em: 24/06/2016.

DIREITO DE RESPOSTA. Associação dos Magistrados Paranaenses (AMAPAR) e Associação Paranaense do Ministério Público (APMP). 25 fevereiro 2016. Disponível em: <http://www.amapar.com.br/imprensa/noticias/item/direito-de-resposta-conferido-à-amapar-e-à-apmp.html>. Acesso em: 22/06/2016.

DWORKIN, Ronald. O direito da liberdade: a leitura moral da Constituição norte-americana. Trad. Marcelo Brandão Cipolla. São Paulo: Martins Fontes, 2006.

FARIAS, Edilsom Pereira de. Colisão de Direitos: a honra, a intimidade, a vida privada e a imagem versus a liberdade de expressão e informação. Sergio Antonio Fabris Editor: Porto Alegre, 1996.

FIRST AMENDMENT. FREEDOM OF RELIGION, PRESS, EXPRESSION. First Amendment Center. Disponível em: <http://www.firstamendmentcenter.org/about-the-first-amendment $>$. Acesso em: 10/06/2016.

FISS, Owen M. A ironia da liberdade de expressão: estado, regulação e diversidade na esfera pública. Trad. Gustavo Binenbojm e Caio Mário da Silva Pereira Neto. Rio de Janeiro: Renovar, 2005.

GOMIDE, Raphael; SALLES, Lívia Cunto. Juízes estaduais e promotores: eles ganham 23 vezes mais que você. Época. 12 junho 2015. Disponível em: <http://epoca.globo.com/tempo/noticia/2015/06/juizes-estaduais-epromotores-eles-ganham-23-vezes-mais-do-que-voce.html>. Acesso em: 10/06/2016.

MARÉS, Chico; GARCIA, Euclides Lucas; GALINDO, Rogerio Waldrigues; BALMANT, Evandro; STORCK, Guilherme. TJ e MP pagam supersalários que superam em $20 \%$ o teto previsto em lei. Gazeta do Povo. Paraná. 15 fevereiro 2016. Disponível em: <http://www.gazetadopovo.com.br/vida-publica/tj-e-mp-pagam-supersalariosque-superam-em-20-o-teto-previsto-em-lei-8p4mx7sxjoglr9rivs1 hlrig7>. Acesso em: 11/06/2016.

MEIRELLES, Hely Lopes. Direito Administrativo Brasileiro. 26a ed. São Paulo: Malheiros Editores, 2001.

MENDEL, Toby. Liberdade de informação: um estudo de direito comparado. 2.ed. Brasília: UNESCO, 2009. vol.10, no. 01, Rio de Janeiro, 2017.pp. 219-240 
Disponível <http://portal.unesco.org/ci/en/files/26159/126398551119freedom_information_pt.pdf/freedom_informati on_pt.pdf $>$. Acesso em: 03/06/2016.

\section{NOTA DE ESCLARECIMENTO. Associação dos Magistrados Paranaenses e Associação Paranaense do Ministério Público. 17 fevereiro 2016. Disponível em: $<$ http://www.amapar.com.br/imprensa/noticias/item/amapar-e-apmp-emitem-nota-de-esclarecimento-em- face-de-mat $\% \mathrm{C} 3 \% \mathrm{~A} 9$ ria-jornal\%C $3 \% \mathrm{AD}$ stica-que-trata-dos-vencimentos-de-magistrados-e-membros-do- mp.html . Acesso em: 22/06/2016.}

OYEZ PROJECT. Portal do Oyez Project/Chicago-Kent College of Law. Disponível em: <http://www.oyez.org>. Último Acesso em: 10/06/2016.

PUBLIC'S RIGHT TO KNOW. Article 19. Policy Brief. 01 junho 1999. Disponível em: $<$ https://www.article19.org/resources.php/resource/1797/en/>. Acesso em: 28/06/2016.

ROCHA, Graciliano. Projeto do STF cria auxílios do berço ao caixão para magistrados. Folha de São Paulo. 24 maio 2015. Disponível em: <http://wwwl.folha.uol.com.br/poder/2015/05/1632911-projetos-do-stf-criamauxilios-do-berco-ao-caixao-para-magistrados.shtml $>$. Acesso em: 11/06/2016.

SAMPAIO, José Adércio Leite. A Constituição Reinventada pela Jurisdição Constitucional. Belo Horizonte: Del Rey, 2002.

SARMENTO, Daniel. "Liberdades Comunicativas e "Direito ao Esquecimento" na ordem constitucional brasileira”. In: Parecer. Rio de Janeiro. 22 janeiro 2015, pp. 01-50. Disponível em: <http://www.migalhas.com.br/arquivos/2015/2/art20150213-09.pdf>. Acesso em: 01/06/2016.

"Liberdade de expressão, pluralismo e o papel promocional do Estado". In: Revista Diálogo Jurídico. Salvador, Bahia. Brasil. No.16, maio/junho/julho/agosto. 2007, pp. 01-39. Disponível em: $<$ http://www.direitopublico.com.br/pdf_seguro/LIBERDADE_DE_EXPRESS_O_PLURALISMO_E_O _PAPEL_PROMOCIONAL_DO_ESTADO.pdf >. Acesso em: 02/06/2016.

SCHAUER, Frederick. "Fear, Risk and the First Amendment: Unraveling the Chilling Effect". In: Boston University Law Review. Vol. 58. 1978, pp. 685-732. Disponível em: <http://scholarship.law.wm.edu/cgi/viewcontent.cgi?article=2010\&context=facpubs $>$. Acesso em: 04/06/2016.

SIEGEL, Stephen A. "The Origin of the Compelling State Interest Test and Strict Scrutiny". In: The American Journal of Legal History, Vol. 48, i. 4, 2006, pp. 355-407. Disponível em: <http://ssrn.com/abstract=934795>. Acesso em: 05q06/2014.

SMOLLA, Rodney A. "The First Amendment, Journalists, and Sources: A Curious Study in 'Reverse Federalism". In: Cardozo Law Review. Vol. 29:4. 2008, pp. 1423-1430. Disponível em: <http://scholarlycommons.law.wlu.edu/wlufac/446/>. Acesso em: 04/06/2016.

STF SUSPENDE AÇÕES. Portal do Supremo Tribunal Federal - Notícias do STF. Sexta-Feira, 01 de julho 2016. Disponível em: <http://www.stf.jus.br/portal/cms/verNoticiaDetalhe.asp?idConteudo=320185>. Acesso em: 02/07/2016.

SUPERIOR TRIBUNAL DE JUSTIÇA. Portal STJ (Jurisprudência). Disponível em: $<$ http://www.stj.jus.br/SCON/pesquisar.jsp?newsession=yes\&tipo_visualizacao=RESUMO\&b=ACOR\&livre 
=liberdade+de+imprensa+veracidade>. Último acesso em: 28/06/2016.

SUPREMO TRIBUNAL FEDERAL. Portal STF (Inteiro Teor). Disponível em: <http://www.stf.jus.br/portal/inteiroTeor/pesquisarInteiroTeor.asp>.Último acesso em 28/06/2016.

UNITED STATES CONSTITUTION. Portal USConstitution. Disponível em: <http://www.usconstitution.net.> Acesso em: 10/06/2016.

UNITED STATES SUPREME COURT CENTER. Portal Justia.Com. Disponível em: $<$ http://supreme.justia.com/>. Último Acesso em: 28/06/2016.

UNITED STATES SUPREME COURT. Baumgartner v. United States. Opinion of the Court: Justice Frankfurter, 1944.

Thomas v. Collins. Opinion of the Court: Justice Rutledge, 1945.

National Association for the Advancement of Colored People (NAACP) v. Button. Opinion of the Court: Justice Brennan, 1963.

New York Times Co.v. Sullivan. Opinion of the Court: Justice Brennan, 1964.

Curtis Publishing. Co.v. Butts. Authored by: Justice John Harlan, 1967.

Branzburg v. Hayes. Opinion of the Court: Justice White, 1972.

Gertz v. Robert Welch, Inc.. Opinion of the Court: Justice Powell, 1974.

Hustler Magazine, Inc. v. Falwell Opinion of the Court: Chief Justice Rehnquist, 1988.

WATERGATE AT 40. The Washington Post. Disponível em: <https://www.washingtonpost.com/politics/watergate/>. Acesso em: 20/06/2016.

YOUN, Monica. "The Chilling Effect and the Problem of Private Action". In: Vanderbilt Law Review. Vol. 66:5. 2013, pp.1473-1539. Disponível em: <https://www.vanderbiltlawreview.org/2013/10/the-chilling-effect-andthe-problem-of-private-action/>. Acesso em: 04/06/2016.

Trabalho enviado em 05 de julho de 2016.

Aceito em 10 de outubro de 2016. 